\title{
Influence of Gender and Location on Students' Achievement in Chemical Bonding
}

\section{Eugene U. Okorie ${ }^{1}$}

\author{
D. N. Ezeh² \\ 1,2Department of Science Education, University of Nigeria, Nsukka; '1eugene.okorie@unn.edu.ng \\ *Corresponding author: eugene.okorie@unn.edu.ng
}

\section{Doi:10.5901/mjss.2016.v7n3p309}

\section{Abstract}

\begin{abstract}
Is students' achievement in chemical bonding a function of their gender and school location? This question and two hypotheses guided the study. Pre-test-post-test non-equivalent control group quasi-experimental design was used, with a population of 5,966 senior secondary class one (SS1) chemistry students in 57 senior secondary schools in Nsukka education zone of Enugu State, Nigeria. Adopting purposive sampling technique, nine schools were selected to draw 311 SS1 students. Intact classes were used. Instruments for data collection were Students' Interest Scale on Chemical Bonding (SISCB) and Chemical Bonding Achievement Test (CBAT). The instruments were validated and had reliability coefficients of 0.68 and 0.87 respectively. Regular chemistry teachers of the selected schools taught the students using instructional software package method of teaching (ISPMT). Research questions were answered, using descriptive statistics. The hypotheses were tested using analysis of covariance (ANCOVA) at $P<0.05$ level of significance. Result of the study showed that $(i)$ mean achievement score (10.09) of female students was higher than that (8.02) scored by the male students; (ii) mean achievement score of rural students (9.06) was higher than that of the urban students (8.76); (iii) gender as a main effect on students' achievement in chemical bonding is not significant at $p<0.05$; and (iv) location as a main effect on students' achievement in chemical bonding is significant at $p<0.05$. The educational implications of the research findings for students, teachers and teacher-training institutions are discussed and recommendations made.
\end{abstract}

Keywords: Gender, school location, achievement, chemical bonding

\section{Introduction}

Academic achievement of students has often been associated with their gender and location. Gender refers to the fact of being male or female (Pearson Education, 2003). Kanno (2008) referred to gender as an analytic concept that describes sociological roles, cultural responsibilities and expectations of men and women in a given society or cultural setting. Ezeh (2013) explains that 'gender describes the personality traits, attitudes, behaviours, values, relative power, influence, roles and expectation (femininity and masculinity) that society ascribes to the two sexes on a differential basis'. Therefore, gender is a psychological term and a cultural construct developed by society to differentiate between the roles, behaviour, mental and emotional attributes of males and females. The influence of gender on learning and achievement has remained a controversial and topical issue amongst educationists and psychologists. Freud (1958) suggested that the difference in male and female anatomy has bearing and indeed account for the difference observed between the personalities of men and women. It is from the Freudian theory that several gender-related studies have taken their roots.

\subsection{Statement of the problem}

It is suspected that for most adolescents in secondary schools, cultural and societal expectation alongside career prospects and opportunities within the socio-cultural melee are factors that play a major role in their individual choice of career and vocations. For those of them who elect to study chemistry related courses, they study chemistry because it is required for their future career development, to enable them play the role their culture and society expect of them. Herein lies the issue of gender, defined as biased role expectation of culture and society, ascribed based on being males or females. Gender role stereotyping continues to permeate our society and culture; and as it were, determines the extent of progress and achievement in the adolescents' chosen field of endeavour. For adolescent beginning students of chemistry in secondary schools, chemical bonding is a difficult chemistry concept. A difficult chemistry concept is one which students find difficult to understand and teachers find difficult to teach. The abstract nature of the concept and the 
pedagogical approach adopted by teachers in presenting the concept to the students have often be blamed for students' difficulty in understanding and underachievement in this particular concept and chemistry generally. Some studies blame school locations for students' underachievement in chemistry, arguing that there is disparity in educational opportunities available to those who reside in rural and urban areas, because of disparity in distribution of educational facilities and material including personnel in favoured of urban schools. The question then arises: is students' achievement in chemical bonding a function of the influence of their gender and school location? This is the problem of this study.

\section{Literature Review}

In a study, Eze (2008) asserted that gender had significant effects on students' achievement in chemistry, and showed that male students achieved higher than their female counterparts did. Owoyemi (2007) asserted that student's achievement in chemistry course has 'nothing to do with whether the student is male or female'. Adigwe (1992) showed that male students perform better in both achievement and acquisition of problem solving skills than female students in chemistry. Ahiakwo (1988) showed that girls performed better than boys in chemistry, and that the difference between their mean achievement score was significant. Trigwell (1990) found that male students were superior over female students in problem-solving and achievement in chemistry. Erinosho (1994) cited in Adesoji and Babatunde (2008) showed that the difference between the mean achievement scores of female and male students was not statistically significant in chemistry. Agbir (2004) found that gender was not a significant factor in the overall mean achievement rating of students in practical skills on acid-base titration. Ifeakor (2005) showed a significant gender-related difference in students' cognitive achievement in favour of male students over their female counterparts. Ssempala (2005) investigated gender differences in the performance of practical skills on quantitative analysis, an aspect of chemistry, among senior secondary school girls and boys in selected co-educational schools. The author showed that there were no statistical significant differences between girls and boys in their ability to manipulate the apparatus/equipment, take observation, report/record results correctly, and compute/interpret/analyse results during chemistry practical; girls performed slightly better than boys overall; boys performed slightly than the girls in the following skills: recording/reporting results correctly, and computing/interpreting/analysing results. Eze (2008) studied the effect of two questioning techniques on students' achievement, retention and interest in chemistry and found that gender had significant effects on students' achievement; male students achieved higher than their female counterparts did.

It would appear, from the above studies, that gender as an influencing factor in learning and achievement in aspects of chemistry remains important but controversial. None of the reviewed studies was on chemical bonding; this leaves a gap in knowledge, thus creating a need for this present study.

School location refers to the particular place, in relation to other areas in the physical environment (rural or urban), where the school is sited. In Nigeria, rural life is uniform, homogenous and less complex than that of urban centres, with cultural diversity, which often is suspected to affect students' academic achievement. This is because urban centres are better favoured with respect to distribution of social amenities such as pipe borne water, electricity, healthcare facilities while the rural areas are less favoured. This is also true in the distribution of educational facilities and teachers. These prevailing conditions imply that 'learning opportunities in Nigerian schools differ from school to school' (Ariyo and Ugodulunwa, 2007). It would appear therefore that students in Nigerian urban schools have more educational opportunities than their counterparts in rural schools have. While some studies have shown positive influence, others have shown negative influence of school location on the students' learning outcome or achievement. Nwogu (2010) found that location was significant in learning aspects of mathematics that involve angles, with rural students exhibiting more learning difficulties than their urban counterparts do. Ahiaba and Igweonwu (2003) investigated the influence of school location on the performance of chemistry students in rural and urban schools at the SSC examination and found that chemistry students in urban schools performed better with superior grades, than their rural counterparts while failure rate was higher in the rural schools. Some studies (Bosede, 2010; Ezeh, 1998) showed no difference in academic achievement of students because of location. Agbir (2004) showed that rural students performed better on practical skills in chemistry than their urban counterparts did. The influence of location on students' academic achievement remains controversial and inconclusive. This calls for further investigation.

Bosede (2010) showed that there is no difference in performance of students because of location. Location here is in terms of whether the place of study or school is sited in rural or urban community. Onah (2011) showed that urban students achieved more than the rural students did. No available literature from empirical studies explained if there is any differential performance because of gender and location in chemical bonding.

In evaluating learning outcome, the effect of gender and school location on learning and hence achievement in a teaching-learning process is often not taken into consideration. Curriculum designers and examination bodies do not 
make allowance for differences in school location and gender, hence students, irrespective of their gender and school location are subjected to the same teaching curriculum, teaching method and examination in a given subject. It is expected that teachers should be conscious of, and make allowances during classroom activities for differences in school location and gender. It is recognised that differences exist in the way individuals react to learning situations and materials. Davis (1977) noted that teaching and learning can take place anywhere (rural or urban), and at any time insofar as there is communication between the teacher, the learner and the learning material. In this study, the chemical bonding Instructional Software package developed for it constituted the interactive multimedia that provided a platform for communication and interaction between the learning material and the learners, irrespective of their gender and location.

\section{Research Design}

This study used a used a two-factor pretest-posttest non-equivalent non-randomised quasi-experimental control group design. Nworgu (2006) refers to quasi-experimental design as one which 'random assignment of subjects to experiment and control groups is not possible. In this, intact or pre-existing groups are used.' The present study fits into the conventional definition of quasi-experimental designs. This is because intact or pre-existing groups were used. In particular, different schools used served as experimental as well as control groups to each other; and two levels of treatment were involved. Non-equivalent factorial design proves most useful in situations where, constraints, subjects could not be randomly assigned to treatment (Campbell and Stanly, 1986). The constraint in this study had to do with school location and regulations. It was better to allow the students to remain in their existing natural setting, their usual classrooms, and under the guidance of their regular classroom teachers. This is the reason for the choice of this particular research design.

Symbolically, the design is

$\mathrm{O}_{1} \times \mathrm{O}_{2}$

$\mathrm{O}_{1} \times \mathrm{O}_{2}$

Where, $\mathrm{O}_{1}=$ pretest observation

$\mathrm{O}_{2}=$ posttest observation

$X=$ the treatment

subjects to conditions.

---- = an indication that the treatment and control groups used were not arrived at by random assignment of

The dependent variable of this study was the teaching method while the independent variables were students' gender, school location and their achievement in chemical bonding.

\subsection{Area of Study}

The area of study was Nsukka Education zone of Enugu state, Nigeria. Nsukka Education zone is made up of three local government areas, namely Igbo-Etiti, Nsukka and Uzo-Uwani. The zone has 58 secondary schools controlled by the same education authority - the State Post-primary Schools Management Board. The schools are distributed as follows: Igbo-Etiti: 16; Nsukka: 30; and Uzo-Uwani: 12. All the schools, except one, offer chemistry at the senior school certificate level. Therefore, only 57 of the 58 secondary schools were available for this study. The choice of the zone for this study was in consideration of the homogeneous nature of the schools in the zone. All the schools are under the same education authority. Besides, it was convenient for the researcher to effectively manage financial resources available for the study. The researcher had to visit all the schools involved in the study on regular basis throughout the study period, to monitor the activities of the cooperating classroom teachers, and hence ensure that they were in line with the agreed plans of the study.

\subsubsection{Population for the study}

The population consisted of 5,966 senior secondary class one (SS1) students studying chemistry in Nsukka Education zone during the 2012/2013 academic session. This figure was obtained from the Nsukka zone office of Enugu State Postprimary Schools Management Board. The choice of this grade of students was because chemical bonding, the concept that both students and their teachers regard as a difficult one, is located in SS1 section of the NERDC curriculum in use in Nigerian schools for senior secondary school chemistry. 


\subsubsection{Sample and Sampling Techniques}

The sample consisted of 311 SS1 students drawn from nine senior secondary schools in Nsukka education zone of Enugu State, Nigeria, five of the schools located in the urban centre formed the urban group while the rural group consisted of four schools located in rural areas of the zone. For the urban group, an additional school became necessary in order to have a sizable number of students close to that of the rural group. Purposive sampling technique was used for selection of schools, based on the following criteria: availability of ICT facilities such as computer and overhead projectors; ability of teachers to perform basic operations using the afore mentioned ICT facilities.

\subsubsection{Instruments for Data Collection}

Two instruments namely, Students' Interest Scale on Chemical Bonding (SISCB) and Chemical Bonding Achievement Test (CBAT) were used in this study. The SISCB is a questionnaire developed by the researcher. It is a four point Likerttype scale, containing fourteen items, with four response options. The response options are Strongly Agree, Agree, Disagree and Strongly Disagree. On the scale, Strongly Agree $=4$, Agree $=3$, Disagree $=2$ and Strongly Disagree $=1$, for positive statements and were reversed for negative statements. The SISCB was face validated by three experts from the University of Nigeria, Nsukka comprising one measurement and evaluation expert and two chemical educators. The experts assessed the following:

(i) If the statements were clear, unambiguous and easy to interpret.

(ii) If the statements actually reflected solicited expression of interest.

(iii) If some of the statements overlapped.

The experts were requested to suggest changes that could be made to improve the instrument. The comments of the experts guided and determined the modification that was made in the instrument before using it.

The Chemical Bonding Achievement Test (CBAT) was used to assess the effect of instructional software package method of teaching (ISPMT) on the learning of students. The Chemical Bonding Achievements Test (CBAT) is a 20 items multiple-choice test drawn from various chemical bonding units as recommend by the NERDC curriculum for SS1 chemistry. The instrument was developed by the researcher. Each test item in the instrument has four response options namely $A, B, C$ and $D$, with only one option as the key while others are distracters. The SISCB was face validated. The reliability of CBAT was 0.87 , calculated using Kuder Richardson formula 20 and that of SISCB was 0.68 , calculated using Cronbach alpha method.

\section{Experimental Procedures}

The researcher trained regular chemistry teachers of the selected schools on the use of Instructional Software Package Method of Teaching (ISPMT). ISPMT is described fully elsewhere (Okorie, 2015). Briefly, Instructional Software Package Method of Teaching (ISPMT) is a relatively emerging pedagogical approach in Nigeria. It involves guiding students and making necessary explanations to the learners only on request, as the students learn on their own with the aid of the computer, using instructional software packages. The software package provides an interactive educational environment enriched with images, animated clips, voice recordings and written word. It is designed essentially for students in a selfdirected learning situation. However, in a classroom application the teacher uses the package to facilitate the teachinglearning process. In this case, the teacher plays specific but minimal role in the teaching-learning activities, while the learners themselves carry out much of the activities that result in learning.

The training lasted for one week. The teachers received training on how to use the chemical bonding instructional software package (CBISP) for teaching. CBISP is tailored to the curriculum needs of the students. Each of the teachers received a copy of the CBISP for teaching. Before treatment commenced, the researcher administered SISCB and CBAT to the students, as pre-test and recorded their score. The treatment for the study was teaching, using the Instructional Software Package Method of Teaching (ISPMT), and this lasted for five weeks.

\subsection{How the Learners used the CBISP}

The students arranged themselves in groups of five students per group. One student from one of the groups inserted the $C D$ containing the lesson into the computer $C D$ drive and operated the computer such that the lesson was projected on a large screen in the classroom. All the students listened to, and watched the lesson on the screen; they wrote down their observations, thinking and questions, which they discussed amongst themselves after 15 minutes interval of watching 
and listening to the lesson on the screen. The discussion normally lasted for about five minutes after which time the lesson was allowed to go on to completion. The duration of the discussion sometimes extended beyond five minutes, but never exceeded ten minutes, depending on the nature of interaction amongst the students that sometimes may call for the attention of the teacher. At the end of the lesson, another discussion took place, followed by quiz and assessment test on the screen.

To answer any question, students in their various groups would reach a common consensus as to which of the provided options is the answer to the multiple-choice question. However, each student answers the question based on personal conviction. In this particular study, and for mixed sex schools, student discussion break-out was organized such that female and male students discussed in their separate single-sex groups. It was assumed that the effect of the student discussion break-out would be reflected on their performance in the achievement test.

Three periods of 40 minutes each week were used for teaching of the students, following the usual school timetable as was peculiar to each school. During the five weeks duration of the study, teachers for interest, cooperation and participation in class activities closely observed students. The indices of these variables include regular class attendance and in time, preparedness to discuss, full engagement in carrying out class activities including discussions, taking notes and asking questions. The next day, immediately after the completion of treatment, the researcher administered the CBAT again to the students as post-test and their scores were recorded. For this post-test, the various questions in CBAT were rearranged, to eliminate the effect of familiarity with the items in the instruments.

\subsubsection{Method of Data Collection}

The scores obtained by the students in the pre-test were recorded and kept for use at the end of the experiment. At the end of the experiment, post-test (CBAT) was administered to the students. The scores of the post-test were recorded differently. To ascertain and have a good idea about the effect of the high student-student classroom interaction engendered by the ISPMT on the students' achievement, students were interviewed. The students were also asked to air their views on whether gender and their school location have in any way affected their performance in the concept studied.

\subsubsection{Method of Data Analysis}

Mean and standard deviation were used in answering the research questions. The hypotheses were tested, using analysis of covariance (ANCOVA) at 0.05 level of significance. The covariates are the pre-test and post-test scores.

\section{Results}

\subsection{Research question 1: What is the influence of students' gender on their achievement in chemical bonding?}

Table 1: Means and standard deviations of students' scores in post test CBAT (Gender x Achievement).

\begin{tabular}{lccc}
\hline Gender & No of subjects & Mean & Standard Deviation \\
\hline Male & 174 & 8.0230 & 2.9679 \\
Female & 137 & 10.0949 & 3.3582 \\
\hline Total & $\mathbf{3 1 1}$ & $\mathbf{8 . 9 3 6 7}$ & $\mathbf{3 . 3 0 5 3}$ \\
\hline
\end{tabular}

The above data (Table 1) shows that the mean achievement score of male students is 8.0230 while that of the female students is 10.0949. It would appear from the difference in the mean scores that female students scored higher in the CBAT than the male students. In order to ascertain whether this observed difference is real or attributed to error variance, this result was subjected to inferential testing as hereunder shown.

H01: Students' gender is not a significant factor of their mean achievement in chemical bonding. 
Table 2: Analysis of Covariance (ANCOVA) of students' overall achievement scores (Location by Achievement)

\begin{tabular}{lcccccc}
\hline Source of variation & Sum of squares & Df & Mean squares & $\mathrm{F}$ & Significance & Decision at 0.00 level \\
\hline Pre-achievement & 53.628 & 1 & 153.628 & 28.952 & .000 & $\mathrm{~S}$ \\
Main effects & 161.287 & 3 & 53.763 & 10.132 & .000 & $\mathrm{~S}$ \\
Location & 22.502 & 1 & 22.502 & 4.241 & 0.040 & $\mathrm{~S}$ \\
Explained & 1778.894 & 7 & 254.128 & 47.891 & .000 & $\mathrm{~S}$ \\
Residual & 1607.820 & 303 & 5.306 & & & \\
Total & $\mathbf{3 3 9 2 . 6 8 4}$ & $\mathbf{3 1 1}$ & $\mathbf{1 0 . 9 2 5}$ & & & \\
\hline
\end{tabular}

The result in Table 2 shows that gender as a main effect on students' achievement in chemical bonding is not significant at 0.05 . This is because its probability value of 0.73 is shown to be higher than the level of 0.05 at which it is being tested. Therefore, the null hypothesis, $\left(\mathrm{H}_{1}\right)$ of students' gender not being a significant factor of their mean achievement in chemical bonding is accepted at 0.05 level of significance. This implies that the earlier observed difference between the overall mean achievement scores of female and male students as shown in Table 1 is not a real difference, but that which may be attributed to chance.

In the interview, students admitted that the ISPMT was 'interesting' and helped them to 'understand easily' the concept of chemical bonding. The students said gender had in no way influenced their achievement in the test.

\subsection{Research Question 2: What is the influence of school location on the students' achievement in chemical bonding?}

Table 3: Means and standard deviation of students' scores in post-test CBAT (School location x Achievement)

\begin{tabular}{cccc}
\hline Location & No of subjects & Mean & Standard Deviation \\
\hline Urban & 128 & 8.7578 & 3.6409 \\
Rural & 183 & 9.0601 & 3.0530 \\
\hline Total & $\mathbf{3 1 1}$ & $\mathbf{8 . 9 3 5 7}$ & $\mathbf{3 . 3 0 5 3}$ \\
\hline
\end{tabular}

Table 3 shows that the mean achievement score of students' in rural location schools is 9.0601 while that of students in Urban location schools is 8.7578. From the difference in the mean achievement scores, it appears that students in rural location schools scored higher than their urban counterparts in CBAT did.

In order to ascertain whether this observed difference is real or attributed to error variance, this result was subjected to inferential testing as hereunder shown.

Ho2: School location does not significantly influence students' mean achievement in chemical bonding.

Table 4: Analysis of Covariance (ANCOVA) of students' overall achievement scores (Location by Achievement)

\begin{tabular}{lcccccc}
\hline Source of variation & Sum of & squares & Df & Mean squares & $F$ & \multicolumn{2}{l}{ Significance } & Decision at 0.00 level \\
\hline Pre-achievement & 53.628 & 1 & 153.628 & 28.952 & .000 & S \\
Main effects & 161.287 & 3 & 53.763 & 10.132 & .000 & S \\
Location & 22.502 & 1 & 22.502 & 4.241 & 0.040 & S \\
Explained & 1778.894 & 7 & 254.128 & 47.891 & .000 & S \\
Residual & 1607.820 & 303 & 5.306 & & & \\
Total & 3392.684 & 311 & 10.925 & & & \\
Rificant at 0.05 level; NS $=$ Not significant at 0.05 level
\end{tabular}

The result in Table 4 shows that location, as a main effect on students' achievement in chemical bonding is significant. This is because its probability value of 0.00 is shown to be lower than the level of 0.05 at which it is being tested. Therefore, the null hypothesis, $\left(\mathrm{H}_{2}\right)$ of School location not having significant influence on students' mean achievement score in chemical bonding is rejected at 0.05 level of significance. This implies that the earlier observed difference between the overall mean achievement scores of students' in rural location schools and those of students in Urban location schools, as shown in Table 1 is a real difference, which is not attributed to error associated with the study.

In the interview with the students on the influence of location, student were of the opinion that location influenced their achievement. Some of the students were of the opinion that urban students 'get carried away with social media activities which distract them from academic work, they have ICT facilities and electricity regularly'. 'It is common to see 
students browsing, chatting or playing games with their cell phones or computer while instruction is going on in the classes'. Other students opined that 'students in the rural areas are keen to school in the urban areas, they believe that if they do well academically they may have the opportunity to do so. As a result, they study harder than those students in urban school'. 'Besides, the technologies and other social amenities that distract urban students are lacking in rural areas.

\subsection{Summary of Finding}

1. Gender has no statistically significant effect on students' achievement in chemical bonding.

2. School location has statistically significant effect on students' mean achievement in chemistry.

\section{Discussion of the Findings of the Study}

The discussion is organised under the following sub-headings:

- Effect of gender on students' achievement in chemical bonding

- Effect of location on students' achievement in chemical bonding;

\subsection{Influence of gender on students' achievement in Chemical Bonding}

The result of this study shows that gender, as a main effect has no significant effect on students' achievement in chemical bonding. As shown in Table 1, female students had higher overall mean score of 10.09 as against the male students' overall mean score of 8.02 in Chemical Bonding Achievement Test (CBAT). This result was subjected to inferential testing, against the backdrop of the results in Table 2 where gender, as a main effect, showed a higher probability value of 0.73 at which this main effect is shown not significant, than the level of 0.05 at which it was tested. This implies that gender is not a significant factor in students' achievement in chemical bonding. This finding however disagrees with Trigwell (1990), but agrees with Inyang and Jegede (1994), and Erinosho (1994) reported in Adesoji and Babatunde (2008). Trigwell (1990) found that male students were superior over female students in problem-solving and achievement in chemistry while Inyang and Jegede (1994) reported that gender has no effect on students' achievement in science. Erinosho (1994) cited in Adesoji and Babatunde (2008) reported that the difference between the mean achievement scores of female and male students was not statistically significant in chemistry. Also, Agbir (2004) found that gender was not a significant factor in the overall mean achievement rating of students in practical skills on acid-base titration. Similarly, Ssempala (2004) asserted that there were no statistically significant difference between girls and boys in their ability to manipulate apparatus/equipment, take observation report/record results correctly, and compute/interpret/archive results during chemistry practical. The report further showed that girls performed slightly better than boys did overall.

But contrary to the above findings, Ahiakwo (1988) showed that girls performed better than boys and that the difference between their mean achievement score was significant beyond $P<0.001$ and concluded that there is gender difference in achievement in chemistry process skill test. Ifeakor (2005) showed a significant gender-related difference in students' cognitive achievement in favour of male students over their female counterparts. Also, Ariyo and Ugodulunwa (2007) showed that gender of students was a significant factor in their overall performance on both chemistry and Science General Aptitude Test (SGAT), where the mean achievement of females exceeded that of males.

Three classes of results regarding gender-related differences in achievement in chemistry and science generally can be distinguished from these studies mentioned above, including the present one. The first is one in which there is significant difference in favour of female students (Ahiakwo, 1988); the second class is that in which gender related impact favours the male (Trigwell, 1990; Ifeakor, 2005; Ariyo and Ugodulunwa, 2007); the third class is that in which there is no significant difference.

In the present study, it has been shown that female students' overall mean achievement was higher than that of the male students even though statistically, gender was shown not to be a significant factor in students' achievement in chemical bonding.

\subsection{Influence of School Location on Students' Achievement in Chemical Bonding}

This study showed that students' mean achievement score in chemical bonding of students in rural location schools are higher than that of their urban location school counterparts in CBAT. Results in Table 2 confirm this finding, and show that location, as a main effect on students' achievement in chemical bonding is statistically significant. This implies that 
rural students achieved more than their urban counterparts did.

This is not in agreement with Agbir (2004) which showed that rural students performed better on practical skills in chemistry than their urban counterparts did; however, statistically it was shown in the same study that location was not a significant factor in the students' mean achievement in chemistry practical skills. Similarly, Ezeh (1998) showed that students' achievement in integrated science is not influenced by the difference in their physical environment and that there is no statistically significant difference in students' achievement in integrated science 'between urban and rural location schools'. But, Onah (2011) reported a significant difference in students' achievement with respect to school location. It was shown that location had a statistically significant different influence on the students' achievement in agricultural science, where students in urban schools had a higher mean achievement score than students in rural schools.

The result of this present study contradicts Jegede (1984), with regard to the influence of school location on students' academic achievement. Jegede (1984) showed that there was no statistically significant difference between the achievement of urban and rural students in physics, although the mean achievement scores of urban school students were higher than those of the rural schools. The present study has shown that with ISPMT, rural students achieved more than their urban counterparts did. This implies that ISPMT should be of great assistance in reducing location-related differences in students' performance in aspects of ,chemistry especially chemical bonding.

\subsection{Educational Implications of the Findings}

The outcome of this study has a number of educational implications for students, teachers, teacher-training institutions and the ministries of education. These implications are discussed as follows.

The study shows that with ISPMT female students performed better than their male counterparts on CBAT did. It implies that the adoption of ISPMT, and CBISP as an instructional material is most appropriate in bringing about reduction in gender-related differences in students' achievement and in chemical bonding.

\subsection{Recommendations of the study}

The following recommendations are made, because of the implications of the results obtained in this study.

1. Since gender is not a significant factor in students' achievement in chemical bonding, emphasis should therefore be on teaching methods, rather than on the students' gender. This is very important since every student is likely to gain maximally or to the same degree from a particular method.

2. Since ISPMT has been found to be effective and efficacious in improving the quality of achievement of students in chemical bonding, teachers of chemistry should be encouraged to adopt its use in teaching chemical bonding.

3. The use of ISPMT and CBISP requires that both the teachers and students should be proficient in the use of ICT facilities like projectors, especially computers. For this reason, effort in promoting e-learning and computer literacy in the school system should be intensified.

4. Government and other stakeholders in the school system, who can afford to do so, should equip schools with ICT facilities; especially computers to enable students use educational software packages easily.

5. All schools in Nigeria should be connected to the National grid to ensure supply of electricity at cheaper rate, for without it, the use of computers in schools may become a mirage, as dependency on portable electricity generators to power the computers is very expensive and risky. Chances of explosion and fire while using the generators are there. Besides, the generators create a noisy and non-conducive atmosphere for learning, as smoke and fume from the exhaust of the generators filter into the classrooms.

\subsection{Limitations of the Study}

The limited number of schools that had functional computers and other ICT facilities made it difficult for the researcher to use more schools. Besides, schools used were school either connected to the national grid or had standby electricity generator. Even where some of the schools had standby electricity generator, there were periods the researcher had to supply and fuel the generator to be used in the study. This made a cut down on the length of period the students had to use the computer, at least for revision purposes inevitable. This too, may have affected the result of the study.

Since the result is based on the sample drawn from a limited population in a particular geographical location and education zone in Enugu state, its generalisation is therefore limited, and therefore cannot be compared with another 
result that may be obtained from a similar research that uses a larger population involving the whole state or Nigeria as a whole.

\section{Suggestion for Further Studies}

A number of areas of interest for further studies emerged from the findings of this research. Based on this, the following suggestions are made:

1. Replicate this study, using a larger population and a wider geographical area, where possible, the entire Enugu State or another state in Nigeria.

2. Investigate and ascertain underlying factors that influenced rural students to achieve higher mean score than their urban counterparts did in chemical bonding, when both groups of students were exposed to the same educational software package method of teaching.

\section{References}

Adesoji, F.A \& Babatunde, A.G. (2008). Investigating gender difficulties and misconceptions in inorganic chemistry at the senior secondary level. International Journal of African \& African American Studies. Vii (1), 1-7.

Adigwe, J. C. (1992). Gender differences in chemical problem solving among Nigerian students. Research Education. 10(2). 187 - 201.

Agbir, J. D. (2004). Development and validation of an instrument for evaluating chemistry practical skills for senior secondary schools. Unpublished M.Ed thesis, University of Nigeria, Nsukka.

Ahiaba, J. \& Igweonwu, R.N. (2003). A comparative study of the performance of boys and girls in SSCE science subjects in Dekina L.G.A. of Kogi State. Unpublished Bachelor of Science Education (B.Sc. Ed) project. Department of Science Education, Faculty of Education, University of Nigeria, Nsukka.

Ahiakwo, M.J. (1998). Cognitive style and students' problem-solving behaviour in chemistry. Unpublished Ph.D thesis. Department of Teacher Education, University of Ibadan.

Ariyo, A. O. \& Ugodulunwa, C. O. (2007). Effects of gender and school type factor on Nigerian junior secondary school students' performance in a science general aptitude test. African Journal of Educational Research 11(1\&2), 1-9.

Bosede, A. F.(2010).Influence of sex and location on relationship between students problems and academic performance. The Social Science. 5(4), $340-345$.

Campbell, D.T and Stanley, J.C (1986). Experimental and quasi-experimental designs for research. Boston: Houghton Miflin Company.

Davis, B. (1977). Why teaching isn't possible. Educational Theory 27(4), 305.

Eze, C.C. (2008). Comparative effects of two questioning techniques on students' achievement, retention and interest in chemistry. M.Ed. project report. Department of Science Education, University of Nigeria, Nsukka.

Ezeh, D.N. (1998). Nigerian ethnic language groups and achievement in integrated science among junior secondary school students: implications for integrated science teaching. Conference Proceeding of the 39th Annual Conference of Science Teachers Association of Nigeria , 201-205.

Ezeh, D.N. (2013). Science without women: a paradox. $75^{\text {th }}$ Inaugural Lecture of the University of Nigeria, Nsukka delivered on $30^{\text {th }}$ May, 2013. Nsukka: University of Nigeria Senate Ceremonials Committee.

Freud, S. (1958). Educational Psychology. Boston: Allyn and Bacon Inc.

Ifeakor, A.C (2005). Effects of commercially produced computer assisted instruction package on students' achievement and interest in secondary school chemistry. Unpublished Ph.D Thesis. University of Nigeria, Nsukka.

Inyang, N. and Jegede, O.J. (1994) Development, Validation and standardization in Integrated Science among Secondary School Students. International Review of Education, 36 (3), 310-319.

Jegede, B.A, (1984). Non-cognitive correlates of secondary school students' achievement in physics. Journal of Science Teachers Association of Nigeria, 22 (2), 78-88.

Kanno, T. N. (2008). Gender neutral nature of modern careers. Paper presented at a workshop organised by Federal Ministry of Education for women and girls, at Owerri from $26^{\text {th }}-28^{\text {th }}$ August, 2008.

Nwogu, E. (2010). An inquiry into the major difficulties expressed / exhibited by junior secondary school students in solving problems involving angles. Unpublished BSc (Education/Mathematics) Project, Department of Science Education, University of Nigeria, Nsukka.

Nworgu, B. G. (2006). Educational research: basic issues and methodology. Nsukka: University Trust Publishers.

Okorie, E. U. (2015,November). Effects of Instructional Software Package Method of Teaching (ISPMT) on Students' Interest and Achievement in Chemical Bonding. Education 2015, 5(6): 158-165. DOI: 10.5923/j.edu.20150506.02

Onah, F.E. (2011). Influence of sex and school location on students' achievement in agricultural science. African Journal of Science and Mathematics Education. 1(1), 96-102.

Owoyemi, T. E. (2007). Mathematics and chemistry senior school certificate results, gender and attitude as predictors of achievement in a physical chemistry course. African Journal of Educational Research, 11 (1\&2), 27 - 34.

(Pearson Education (2003). Longman dictionary of contemporary english (New Edition). Essex: Pearson Education Limited.

Ssempala, F. (2005). Gender differences in performance of chemistry practical skills among senior six students in Kampala District. 
http://www.universalpublishers.com/book.php? method=ISBN\&book=1599427001. Accessed, on 22 June, 2011.

Trigwell, K. (1990). The effects of an alternative science degree programme on the participation of women in the physical science. International Journal of Science Education 12 (1), 25. 